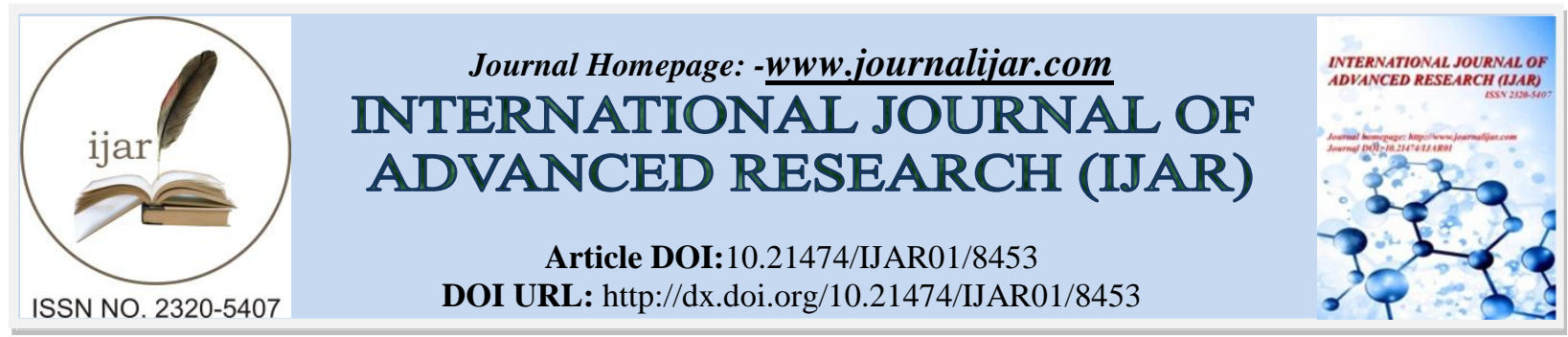

RESEARCH ARTICLE

\title{
ANALYSIS OF BALANCE DYSFUNTION AND FALL RISK IN PATIENTS WITH DAIBETES : AN OBSERVATIONAL STUDY.
}

Srushti v.kulkarni, Chetana Kunde and Suvarna Ganvir.

\section{Manuscript Info}

..........................

Manuscript History

Received: 20 November 2018

Final Accepted: 22 December 2018

Published: January 2019

Key words:-

Diabetic peripheral neuropathy, balance impairment,daibetes,Berg balance scale, time up and go test.
Abstract

Background: Diabetes Mellitus (DM) it is metabolic disorder in which there are high blood sugar levels over a prolonged period. Neuropathies are one of the most common complication of DM. DN may compromise balance during daily activities. Patients with DN have a fivefold increased risk of falling and the consequences include decline in mobility, activity avoidance, institutionalization and mortality

Aims and Objectives: the aim of the study to analysis of balance dysfunction and fall risk in diabetic patients.

Material and method: An observational study was conducted in Dr. Vitthalrao Vikhe Patil Memorial Hospital, Ahmednagar. Also door-todoor patients were taken with type 2 DM in Bhingar. Camps were also held at Vadgoan Gupta \& Gulmohar Road,Ahmednagar. This study also included patients with Type 2 DM attending Dr. Bharat's Diabetic Clinic \& Foot Care, Ahmednagar.80 patients with diabetes were taken. The presence and severity of DN was evaluated using the Michigan Neuropathy Screening Instrument, a tool which allows both diagnosing and severity staging of DN. The balance impairment and the risk of falls were evaluated using two validated and standardized tools: Berg Balance Scale (BBS), Timed-up and Go test (TUG).

Result:According to our study which was done on 80 patients with daibetes with age group 40-50 and 51-60.we found out that there is extreamely significant result which shows patients with diabetic neuropathy had high risk of fall and balance impairment as compared to non neuropathic patients.

Conclusion: The study concluded that there is higher chances of balance dysfunction and fall risk in diabetic neuropathy amongst diabetic people in Ahmednagar City and more and more awareness is necessary to reduce the chances of disability due to diabetic neuropathy.

Copy Right, IJAR, 2017,. All rights reserved.

\section{Introduction:-}

Diabetes Mellitus (DM) it is metabolic disorder in which there are high blood sugar levels over a prolonged period.. The classic symptoms of diabetes are weight loss, polyuria (increased urination), polydipsia (increased thirst), and polyphagia (increased hunger).symptoms may developed rapidly (weeks or months) in type 1 DM while they usually develop much more slowly and may be sutbtal or absent in type $2 \mathrm{DM}$

\section{Corresponding Author:-Srushti v.kulkarni.}


According to WHO, the global prevalence of diabetes among adults over 18 years of age Aaahas risen from $4.7 \%$ in 1980 to $8.5 \%$ in 2014.Also globally an estimated 422 million adults are living with diabetes mellitus according to the latest 2016 data from the world health organization. Its prevalence is increasing rapidly ${ }^{1}$. Diabetes occurs throughout the world but more common in developed countries. The greatest increases in rates has however been seen in low and middle income countries, where more than $80 \%$ of diabetes death occur.

Neuropathies are one of the most common complication of DM. ${ }^{3}$ Boulton AJ, Malik RA. Diabetic neuropathy. Med Clin North Am. July 1998; 82(4):909-29 Diabetic neuropathy affects all peripheral nerves including sensory neurons, motor neurons, and more rarely the autonomic nervous system, symptoms may include trouble with balance

balance is an ability to maintain the line of gravity (vertical line from centre of mass) of a body within the base of support with minimal postural sway.

Maintaining balance requires coordination of input from multiple sensory systems including the vestibular, somatosensory, and visual systems.

Vestibular system: sense organs that regulate equilibrium (equilibrioception); directional information as it relates to head position (internal gravitational, linear, and angular acceleration)

Somatosensory system: senses of proprioception and kinesthesia of joints; information from skin and joints (pressure and vibratory senses); spatial position and movement relative to the support surface; movement and position of different body parts relative to each other

Visual system: Reference to verticality of body and head motion; spatial location relative to objects

DN may compromise balance during daily activities. Patients with DN have a fivefold increased risk of falling ${ }^{5}$ and the consequences include decline in mobility, activity avoidance, institutionalization and mortality ${ }^{6 .}$

This balance impairment in patients with DN is predominantly in the medial-lateral plane and is the greatest during stair descent ${ }^{5}$ Both physiological (strength and proprioception) and cognitive-behavioral factors (fear of falls) should be considered when treating diabetic patients with gait alterations ${ }^{6}$

Diabetic peripheral neuropathy is a disorder of motor ,sensory and autonomic nerves. neuropathic patients are at a greater risk of falling because numbness, decreased sensitivity to touch and muscle weakness can have significant adverse effect on their balance.

Hence, present study focus on evaluating balance dysfunction and fall risk in patients with severity of diabetes.

\section{Material And Methodology:- Methodology:-}

This is an observational study which was conducted at D.V.V.P.F'S Vikhe Patil Memorial hospital, .Also door-todoor patients were taken with type 2 DM in Bhingar. Camps were also held at Vadgoan Gupta \& Gulmohar Road,Ahmednagar. This study also included patients with Type 2 DM attending Dr. Bharat's Diabetic Clinic \& Foot Care, Ahmednagar for a period of one year. 80 subjects were selected for this study by means of simple random sampling. Patients with type 2 DM were included. The age group selected for this study was 40-50 and 5160 year of both the genders.Patients with any other neurological issues., Lower extremities surgeries done in the last 6 months.were excluded.

\section{Procedure:-}

After the approval of Institutional Ethical Committee, of D.V.V.P.F's College of physiotherapy, the subjects were selected based on the inclusion and exclusion criteria and were explained about the study and an informed consent was obtained from all subjects. The demographic data and history of falls was obtained. The screening for DPN was conducted using the Michigan Neuropathy Screening Instrument (MNSI). The MNSI is a validated tool for the 
screening of DPN. The subjects were then explained the procedure of the test. The subjects were then asked to perform BBS and TUG test.

\section{Outcome Measures:-}

Berg balance scale:-

Berg balance scale was used to analysis of balance dysfunction. It consists of a 14 item scale for simple balance tasks (postural changes and positions, transfers and simple object retrieval maneuvers).The ability of performing each task is given a score from 0 (unable) to 4 (independent) and the final result is the sum of all scores; the lower the score the more severe the balance impairment.

\section{Time up and go test:-}

Time up and go (TUG) test measures the time it takes for a patient to rise from an armed chair, walk $3 \mathrm{~m}$, turn and return to sitting in the same chair. Subjects were instructed to walk as quickly as they feel safe and comfortable. The use of the arms of the chair was permitted to stand up and sit down. The TUG test is a simple test used to assess a person's mobility and requires both static and dynamic stability.

\section{Statistical Tests:-}

Correlation coefficient was done to analyse the relationship between Duration of diabetes and Berg balance score and TUG score. To analyse balance dysfunction and fall risk in both the genders, age groups, and neuropathic and non neuropathic groups Mann-Whitney test was used as the data was not equally distributed.

\section{Result:-}

Table 1:-Gender wise Distribution for BBS.

\begin{tabular}{|l|l|l|l|}
\hline & mean \pm SD & P value & Result \\
\hline Male & $44.029 \pm 5.042$ & 0.6435 & Not significant \\
\hline Female & $44.304 \pm 4.921$ & & \\
\hline
\end{tabular}

Table 1 shows that gender wise distribution in which meam \pm SD for male is (44.029 \pm 5.042$)$ and for female is (44.304 \pm 4.921$)$ with $P$ value (0.6435) which shows there is no significant difference between these two groups.

Table 1(a):-Gender wise distribution for TUG.

\begin{tabular}{|l|l|l|l|}
\hline & mean \pm SD & P value & Result \\
\hline Male & $8.703 \pm 1.222$ & 0.2819 & Not significant \\
\hline Female & $9.020 \pm 1.380$ & & \\
\hline
\end{tabular}

Table 1(a) shows that gender wise distribution in which meam \pm SD for male is $(8.703 \pm 1.222)$ and for female is $(9.020 \pm 1.380)$ with $\mathrm{P}$ value $(0.2819)$ which shows there is no significant difference between these two groups.

Table 2:-Age wise distribution for BBS.

\begin{tabular}{|l|l|l|l|}
\hline Age Groups & mean \pm SD & P value & Result \\
\hline $40-50$ & $45.400 \pm 3.947$ & 0.2739 & Not significant \\
\hline $51-60$ & $43.690 \pm 5.252$ & & \\
\hline
\end{tabular}

Table 2 shows that age wise distribution in which meam \pm SD for age group 40-50 is (45.400 \pm 3.947$)$ and age group 51-60 is $(43.690 \pm 5.252)$ with $\mathrm{P}$ value $(0.2739)$ which shows there is no significant difference between these two groups

Table 2(a) :-Age wise distribution for TUG.

\begin{tabular}{|l|l|l|l|}
\hline Age Groups & mean \pm SD & P value & Result \\
\hline $40-50$ & $8.770 \pm 1.598$ & 0.6153 & Not significant \\
\hline $51-60$ & $8.969 \pm 1.211$ & & \\
\hline
\end{tabular}

Table 2(a) shows that age wise distribution in which meam \pm SD for age group 40-50 is (8.770 \pm 1.598$)$ and age group 51-60 is $(8.969 \pm 1.211)$ with $\mathrm{P}$ value $(0.6153)$ which shows there is no significant difference between these two groups 
Table 3:-Neuropathy and without neuropathy for BBS.

\begin{tabular}{|l|l|l|l|}
\hline & mean \pm SD & P value & Result \\
\hline Neuropathy & $42.575 \pm 4.883$ & 0.0003 & Extremely significant \\
\hline Non Neuropathy & $45.95 \pm 4.607$ & & \\
\hline
\end{tabular}

Table 3 shows that distribution between Neuropathy and Non neuropathy groups in which mean \pm SD for neuropathy is $(42.575 \pm 4.883)$ and for non neuropathy $(45.95 \pm 4.607)$ with $\mathrm{P}$ value $(0.0003)$ which shows that there is extremely significant difference between these two groups.

Table 3(a):-Neuropathy and without neuropathy for TUG.

\begin{tabular}{|l|l|l|l|}
\hline & mean \pm SD & P value & Result \\
\hline Neuropathy & $9.4525 \pm 0.8941$ & $<0.0001$ & Extremely significant \\
\hline Non Neuropathy & $8.13 \pm 0.8922$ & & \\
\hline
\end{tabular}

Table 3(a) shows that distribution between Neuropathy and Non neuropathy groups in which mean \pm SD for neuropathy is $(9.4525 \pm 0.8941)$ and for non neuropathy $(8.13 \pm 0.8922)$ with $\mathrm{P}$ value $(<0.0001)$ which shows that there is extremely significant difference between these two groups.

Table 4:-Correlation between Duration of diabetes and Berg balance score and Time up go score in diabetic patients.

\begin{tabular}{|l|l|l|l|}
\hline Scales & Numbers of subjects & Correlation ' $r$ ' & P value \\
\hline Berg balance scale & 80 & -0.2481 & 0.0265 \\
\hline Time Up and Go test & 80 & 0.02978 & 0.7932 \\
\hline
\end{tabular}

Table4 shows that weak negative correlation between Duration of diabetes and Berg balance score i.e.('r' value0.2481 , $\mathrm{P}$ value 0.0265 ), Time up and go score (' $\mathrm{r}$ ' value 0.02987 , $\mathrm{P}$ value 0.7932 ) which indicates the duration of diabetes does not show significant difference in berg balance score and time up and go score.

\section{Discussion:-}

Diabetes is fast gaining the status of a potential epidemic in India with more than 62 million diabetic individuals currently diagnosed with the disease. Diabetic peripheral neuropathy is a common complication of diabetes that can cause significant morbidity and mortality. The present study was conducted to determine the analysis of balance dysfunction and fall risk in diabetic patients in Ahmednagar city. According to our first objective shows that patients with diabetic neuropathy had high risk of fall and balance impairment as compared to non neuropathic patients .these results are calculated using berg balance scale which shows medium and high risk of falls in neuropathic patients. and in time up and go test patients with neuropathy took more time to cover the 3 meter distance than non neuropathic patients. Our study also showed results similar to Bogdan Timar $1^{2}$ et.al. study, where have shown that The presence of DN in patients with DM is associated with impaired balance and with a consecutively increase in the risk of falls. The results of this study are pointing to a significant association between DN and balance impairment and indirectly with the risk of falls in patients with T2DM. It might be due to loss of protective sensations, numbness and tingling in extimites, muscle weakness, burning pain.

Our study also reported that gender wise distribution for balance and we got 34 male and 46 female shows the non significant result. Most probable reason may be due to lack of equal distribution of samples .our study shows there is less number of male samples than female samples due random sampling method. Few studies shows that there is higher chances of balance impairment and fall risk seen in male than females are more susceptible to falling, presumably because they have poorer health and physical fitness than do men. This study demonstrate Males in the study population developed neuropathy earlier than did the female.

Our study shows non significant result between 40-50 and 51-60 Age groups. Statistically it shows negative result but clinically there is more chances of developing neuropathy .in our study more numbers of diabetic patients in 5160 age group than in 40-50 Age group. Most probable reason may be due to lack of equal distribution of samples. our study correlated with the study Gauri Gharote et.al ${ }^{9}$. which shows balance affection and increased risk of falls in 51-60 age group. Most probable reason may be due to age related health issues, deficits in visual, vestibular or somatosensory systems. as the age increases balance alteration and risk of fall also increases while berg balance score decreases,. 
According to our results we found out that there is negative weak correlation between duration of diabetes and berg balance score (' $r$ ' value(-0.2481), $\mathrm{P}$ value- 0.0265 ), and duration of diabetes and time up go score (' $r$ ' value0.02978 , $\mathrm{P}$ value-0.7932). this may be due to in our study we got more numbers of patients suffering from diabetic neuropathy with short duration of diabetes. short duration of the diabetes shows more chances of developing neuropathy in patients it might be due to lack of awareness, lack of medication and poor hygiene.

\section{Conclusion:-}

Diabetic Neuropathy is a nerve damaging disorder associated with Diabetes Mellitus and is one of the most important factors leading to balance dysfunction and fall risk. Thus, the study concluded that there is higher chances of balance dysfunction and fall risk in diabetic neuropathy amongst diabetic people in Ahmednagar City and more and more awareness is necessary to reduce the chances of disability due to diabetic neuropathy. Control of the blood glucose level, modification of lifestyle, physical activity and diet play a major role in reducing the risk of balance dysfunction and fall risk.

\section{References:-}

1. Seema Abhijeet Kaveeshwar1, Jon Cornwall2. The current state of diabetes mellitus in India.1. Bangalore, India 2. University of Otago.Australasian Medical Journal [AMJ 2014, 7, 1, 45-48]

2. Timar B, Timar R, Gaiță L, Oancea C, Levai C, Lungeanu D (2016) The Impact of Diabetic Neuropathy on Balance and on the Risk of Falls in Patients with Type 2 Diabetes Mellitus: A Cross- Sectional Study. PLoS ONE 11(4): e0154654.doi:10.1371/journal.pone.0154654

3. Boulton AJ, Malik RA. Diabetic neuropathy. Med Clin North Am. July 1998; 82(4):909-29

4. Muir SW, Berg K, Chesworth B, Klar N, Speechley M. Quantifying the magnitude of risk for balance

5. impairment on falls in community-dwelling older adults: a systematic review and meta-analysis. J Clin

6. Epidemiol. 2010; 63(4): 389-406. doi: 10.1016/j.jclinepi.2009.06.010 PMID: 19744824

7. Brown SJ, Handsaker JC, Bowling FL, Boulton AJ, Reeves ND. Diabetic peripheral neuropathy compromises

8. balance during daily activities. Diabetes Care. 2015; 38(6): 1116-22. doi: 10.2337/dc14-

9. 1982 PMID: 25765355

10. Hewston P, Deshpande N. Falls and Balance Impairments in Older Adults with Type 2 Diabetes: Thinking

11. Beyond Diabetic Peripheral Neuropathy. Can J Diabetes. 2016; 40(1):6-9. doi: 10.1016/j.jcjd.2015.

12. 08.005 PMID: 26778679

13. Hewston P, Deshpande N. Falls and Balance Impairments in Older Adults with Type 2 Diabetes: Thinking

14. Beyond Diabetic Peripheral Neuropathy. Can J Diabetes. 2016; 40(1):6-9. doi: 10.1016/j.jcjd.2015.

15. 08.005 PMID: 26778679

16. Gauri Gharote ${ }^{1}$, Biradar Vijaykumar ${ }^{2}$, Ujawal Yeole $^{3}$,Praveen Gawali ${ }^{4}$, Roshan Adikitte $^{5}$.Prevalnce of balance alteration in geriatric population using balance scale.2016,vol 4(5):1679-83.ISSN 2321-1822.

17. Greenberg SA. Analysis of measurement tools of fear of falling for high-risk, community-dwelling older

18. adults. Clin Nurs Res. 2012; 21(1):113-30. doi: 10.1177/1054773811433824 PMID: 22373731

19. Mathew S. Maurer, Joyce Burcham, and Huai Cheng Diabetes Mellitus Is Associated With an Increased Risk of Falls in Elderly Residents of a Long-Term Care Facility Journal of Gerontology: MEDICAL SCIENCES Copyright 2005 by The Gerontological Society of America

20. 2005, Vol. 60A, No. 9, 1157-1162

21. International Diabetes Federation. IDF Diabetes Atlas, 7 ed. Brussels, Belgium: International Diabetes Federation, 2015.

22. Mota M, Popa SG, Mota E, Mitrea A, Catrinoiu D, Cheta DM, et al. Prevalence of diabetes mellitus and pre diabetes in the adult Romanian population: PREDATORR study. J Diabetes. 2015 Apr 7. doi: 10.

23. $1111 / 1753-0407.12297$

24. Lagani V, Koumakis L, Chiarugi F, Lakasing E, Tsamardinos I. A systematic review of predictive risk models for diabetes complications based on large scale clinical studies. J Diabetes Complications. 2013; 27(4): 407-13. doi: 10.1016/j.jdiacomp.2012.11.003 PMID: 23273850

25. Giacco F, Brownlee M. Oxidative stress and diabetic complications. Circ Res. 2010; 107(9): 1058- 1070. doi: 10.1161/CIRCRESAHA.110.223545 PMID: 21030723

26. Boulton AJ, Malik RA. Diabetic neuropathy. Med Clin North Am. Jul 1998; 82(4):909-29. PMID: 9706126

27. Dyck PJ, Kratz KM, Karnes JL, Litchy WJ, Klein R, Pach JM, et al. The prevalence by staged severity of various types of diabetic neuropathy, retinopathy, and nephropathy in a population-based cohort: the Rochester Diabetic Neuropathy Study. Neurology. 1993; 43(4): 817-24. PMID: 8469345 
28. Tesfaye S, Selvarajah D, Advances in the epidemiology, pathogenesis and management of diabetic peripheral neuropathy, Diabetes Metab Res Rev. 2012; Suppl 1: 8-14

29. Tahrani AA, Dubb K, Raymond NT, Begum S, Altaf QA, Sadigi H, et al. Cardiac autonomic neuropathy predicts renal function decline in patients with type 2 diabetes: a cohort study. Diabetologia. 2014; 57 (6): 1249-56. doi: 10.1007/s00125-014-3211-2 PMID: 24623102

30. "Diabetes Mellitus"-Wikipedia https://en.m.wikipedia.org/wiki/Diabetes_mellitus Types of diabetes. 